\title{
A LOTERIA DO DIABO: UMA COMÉDIA MÁGICA. O TEATRO COMO LUGAR DA HISTÓRIA E DA MEMÓRIA.
}

\section{Valéria Maria Chaves de Figueiredo - UFG Urânia Auxiliadora Santos Maia de Oliveira - UFBA}

\section{Resumo}

Este artigo relata a montagem de uma adaptação da comédia musical portuguesa do Século XIX, a mágica: A Loteria do Diabo, de Joaquim Augusto de Oliveira, montada por professores e alunos da Escola de Música e Artes Cênicas (EMAC) da UFG. Suscita reflexões nos campos da dança, do teatro e da música e as relações educacionais na produção artística e acadêmica. O trabalho foi desenvolvido na disciplina Oficina do Espetáculo III, do Curso de Artes Cênicas, a partir da adaptação literária da obra e a integração do teatro, da dança e da música, considerando-se as especificidades destas linguagens. A encenação incluiu a pesquisa histórica do gênero, considerando suas características peculiares, como a ilusão criada com efeitos especiais e a presença de uma orquestra acompanhando o coro. A montagem indicou a relevância do diálogo entre as linguagens e o quão delicado é o ato de adaptar uma obra para o universo contemporâneo sem descaracterizá-la.

\section{Palavras-chave:}

Processo de criação; Comédia mágica; Artes integradas.

Este trabalho ${ }^{1}$ teve como origem o desafio de compor estudos transdisciplinares ${ }^{2}$ entre teatro, dança e música, através de uma montagem teatral de um gênero pouco conhecido: a comédia mágica. O espetáculo ocorreu a partir de relações entre algumas áreas do conhecimento que perpassam as noções de educação, de arte, de história e de memória. Na comédia mágica, gênero que não mais existe, tivemos oportunidade de trabalhar com conceitos de coletividade e de memória que serão abordados mais adiante. Nesse momento do texto consideramos importante introduzir a partir dos estudos da pesquisa histórica e artística sobre

\section{Abstract}

This article reports on the staging of an adaptation of the Portuguese musical comedy from the XIX century: the magical: The Devil's Lottery, by Joaquim Augusto de Oliveira, staged by teachers and students from Escola de Música e Artes Cênicas (Emac) - UFG. It rouses reflections in the field of dance, theatre and music and of the educational relations in the artistic and academic production.The work has been developed in the subject Oficina do Espetáculo III from the course Artes Cênicas. It has been developed from the adaptation of the literary work and the integration of theatre, dance and music taking into consideration the specificities of those languages. The staging included the historical research of the genre, considering its peculiar characteristics such as the illusion created with special effects and the presence of an orchestra accompanying the choir. The staging indicates the relevance of the dialogue between the languages and how delicate is the act of adapting a work to the cotemporary world without mischaracterizing it.

Keywords:

Creation process; Magical comedy;

Integrations arts.

as comédias mágicas portuguesas realizadas pelos grupos envolvidos no projeto.

As comédias mágicas foram espetáculos dramático-musicais surgidos em Portugal durante o século $X I X$ e que perduraram até o século $X X$. Esses dramas musicais possuíam características do teatro barroco e do teatro popular português. Existem registros que as comédias mágicas foram espetáculos freqüentes nos teatros do Rio de Janeiro e de Lisboa, e sua característica marcante, como gênero, é a presença de personagens e aspectos fantásticos, ainda que aliados a outros aspectos como os líricos, satíricos, etc ${ }^{3}$. 
Sobre a origem das mágicas sabemos que seu surgimento tanto em Portugal quanto no Brasil apresenta muitas similaridades e parecem ter percorrido três fases distintas: do final do século XVIII e meados do século XIX(1840); de meados do século XIX até 1880 aproximadamente; e deste momento até $1920^{4}$. Fases essas que não foram fechadas e estanques, ao contrário alterenaram as tendências e se adaptaram a atualidade de cada período. As características foram se acetuando à medida que ocorriam uma mesclagem de especificidades. Mas, pode-se afirmar que o traço mais marcante e acentuado que percorreu as três fases foi a presença do ceonceito do fantástico e do maravilhoso.

Ao estudarmos o teatro barroco do século XVII reconhecemos prontamente características similares as da mágica. "A ópera era um meio para o fim, uma oportunidade para a exibição da magia, da decoração e maquinarias barrocas." ${ }^{5}$ Aqui percebemos o mesmo sentido da mágica em proporcionar a ilusão através de truques que geravam efeitos fantásticos. Nesse sentido a transformação é a palavra que define o barroco. Transformação é também a palavra que define a mágica.

Ainda segundo a autora, anúncios em periódicos cariocas e lisboetas apontavam a mágica como um gênero envolvido totalmente com as visualidades e com efeitos fantásticos. Nesses períodicos os maqinistas eram citados nominalmente e com destaque para os efeitos que produziam. De fato essa característica mágica assegurava prontamente a presença do público e funcinava como um chamariz para garantir sempre a casa cheia.

Esses espetáculos ganharam esse nome por apresentarem situações e elementos fantásticos e com temática mitológica. Os cenários eram compostos por maquinarias que criavam efeitos visuais e que encantavam a plateia, como por exemplo, um casebre que se transformava em uma mesquita, um sofá que se transformava em uma cama, uma cama que se transformava em um altar real, etc. Esses efeitos mágicos garantiam não só a aceitação do público, mas sua presença cativa nos teatros.

Em outras palavras, para o teatro barroco em geral, inclusive paraasóperas e outros gêneros dramáticomusicais, o fantástico foi o ingrediente essencial. As mágicas possivelmente deram continuidade a essa característica no século seguinte, chegando a adentrar as duas primeiras décadas do século $X X$. Preservaram tais características, mesmo ao interagir com o individualismo e o subjetivismo do romantismo, a perspectiva social do realismo e a valorização da aparência de realidade presente no naturalismo. Ademais fizeram um contraponto por meio da fantasia, à visão cientifica e objetivista do positivismo, e guardaram, sobretudo na segunda metade do século XIX, a intensa relação com as inovações tecnológicas então ocorridas, como a iluminação elétrica, que, aplicadas a efeitos cênicos requeriam o uso de maquinismos complexos e recursos inéditos. ${ }^{6}$

Nesse sentido podemos fazer um contraponto com as mágicas. Dois séculos depois a mágica preservou o espírito do barroco e se adequou à tecnologia do seu tempo, garantindo sucesso por mais um século e se perpetuando na memória e na história como uma forma de teatro musical. As mágicas "[...] sempre enfatizaram a fantasia; sempre aliaram à presença de personagens e aspectos fantásticos características como o lirismo, a sátira e o humor"7.

Importante destacar ainda que as mágicas conviveram com as óperas durante todo século XIX e o início do século XX compartilhando o mesmo público. Na segunda metade do século $\mathrm{XIX}$, as óperas iniciam seu declínio abrindo espaço para outros tipos de espetáculo visuais como lanternas mágicas ${ }^{8}$ e espetáculos teatrais como vaudevilles ${ }^{9}$, peças realistas, revistas e mágicas.

Sobre a estrutura espetacular das mágicas é interessante destacar que as cenas se apresentavam, na maioria das vezes, de forma independentes em quadros como no teatro medieval. Esses quadros eram constituídos sempre de músicas com distintas características e de textos em português, embora às vezes o enredo se desenrolasse em outro país, como no caso da mágica que será descrita mais adianta que se passa no oriente. Os quadros que compunham as cenas não eram livres, mas possuíam uma ligação mesmo que tênue, embora o enredo não fosse totalmente linear.

Nesse momento do texto consideramos necessário abordar a questão da nomenclatura desse gênero, embora já tenhamos tocado rapidamente nesse tema acima. Acreditamos, após a pesquisa, que o termo "mágica" está diretamente relacionado à questão do encantamento ilusório e das experiências sensoriais que esse estilo de teatro 


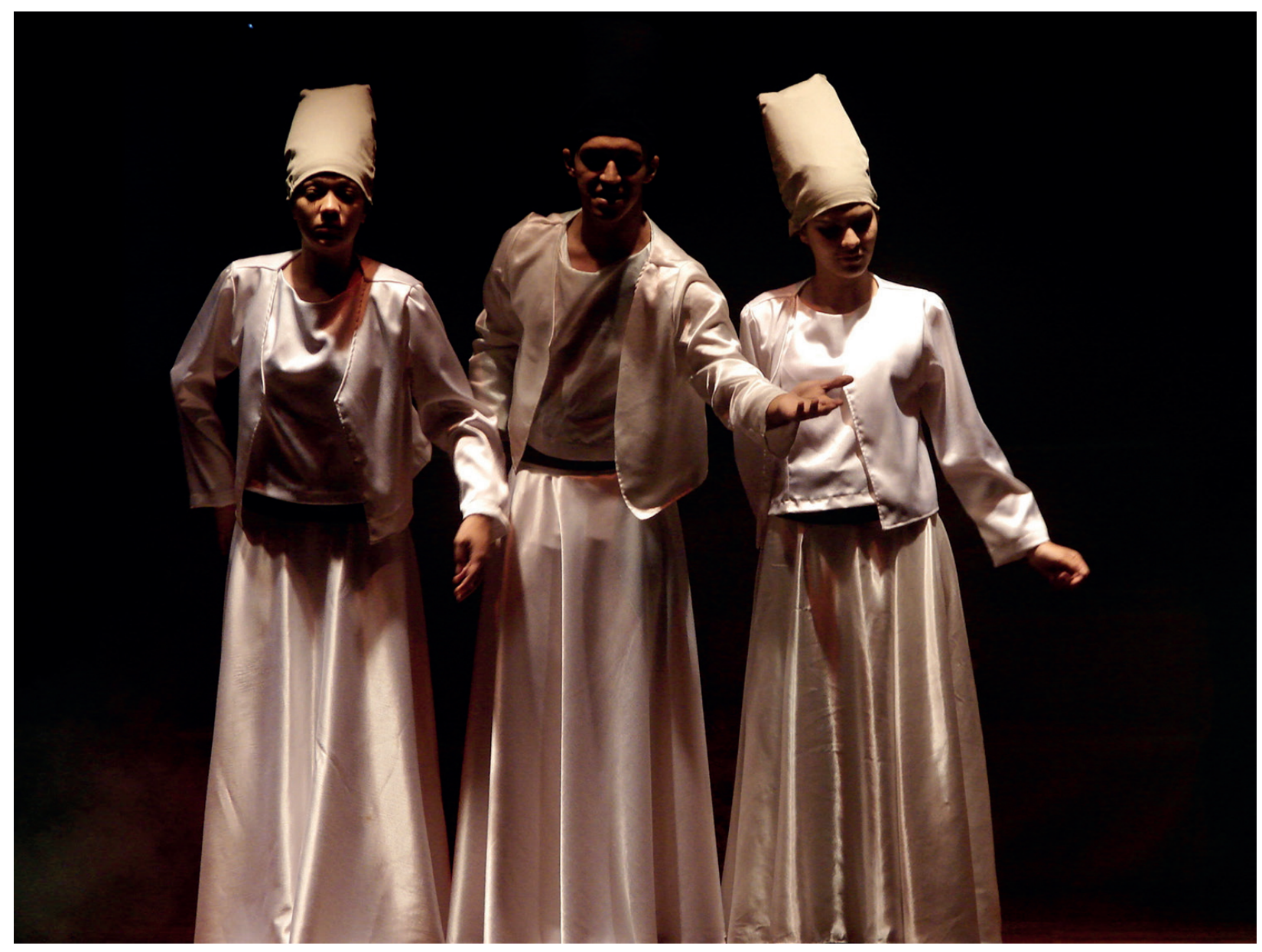

Figura 1 - Alunos do Curso de Teatro da EMAC - EMAC/UFG/Cena dos Dervirxes.

Fonte: Fabrícia Vilarinho.

musical causava no espectador. Em jornais, cartazes e outros documentos da época esse gênero recebeu outras denominações, mas os adjetivos "mágico" e "fantástico" sempre estavam presentes $^{10}$. São citadas em alguns momentos como mágicas, mas também recebeu outras denominações como: operetas fantásticas, comédias mágicas, peças fantásticas ou peças mágicas. Mas, certamente o termo que mais se popularizou foi, de fato, mágica.

Outro aspecto que deve ser mencionado com relação à mágica é a característica do cômico. O humor estava sempre presente e era predominante. A própria narrativa era cômica e o enredo enveredava por esse caminho. Os personagens traziam nas suas falas algo de engraçado e de burlesco. o grotesco também aparece em personagens como os diabos e os seres sobrenaturais.

Ainda outro ponto que consideramos relevante e que merece destaque nesse texto é a questão de quem escreve as mágicas. Dramaturgos e compositores escreveram muitas mágicas com temáticas educativas e abordando valores morais. No Brasil destacamos Henrique Alves de Mesquita, Francisca Gonzaga, Abdon Milanez, Barroso Neto, entre outros. Já em Portugal apontamos Santos Filho, Casimiro Júnior, Augusto Machado, Joaquim Augusto d'Oliveira, entre outros ${ }^{11}$. A mágica que trabalhamos e descreveremos a seguir como objeto de estudo foi escrita pelo português Joaquim Augusto d'Oliveira.

A encenação das mágicas, nos períodos de seu surgimento, ascensão e declínio, eram feita por profissionais que atuavam nas montagens. Eram eles atores, cantores, maestros, ensaiadores, figurinistas, produtores teatrais e maquinistas. O espetáculo na verdade era uma criação coletiva, construído a muitas mãos. Exatamente na mesma estrutura que construímos a experiência que narraremos a seguir. 


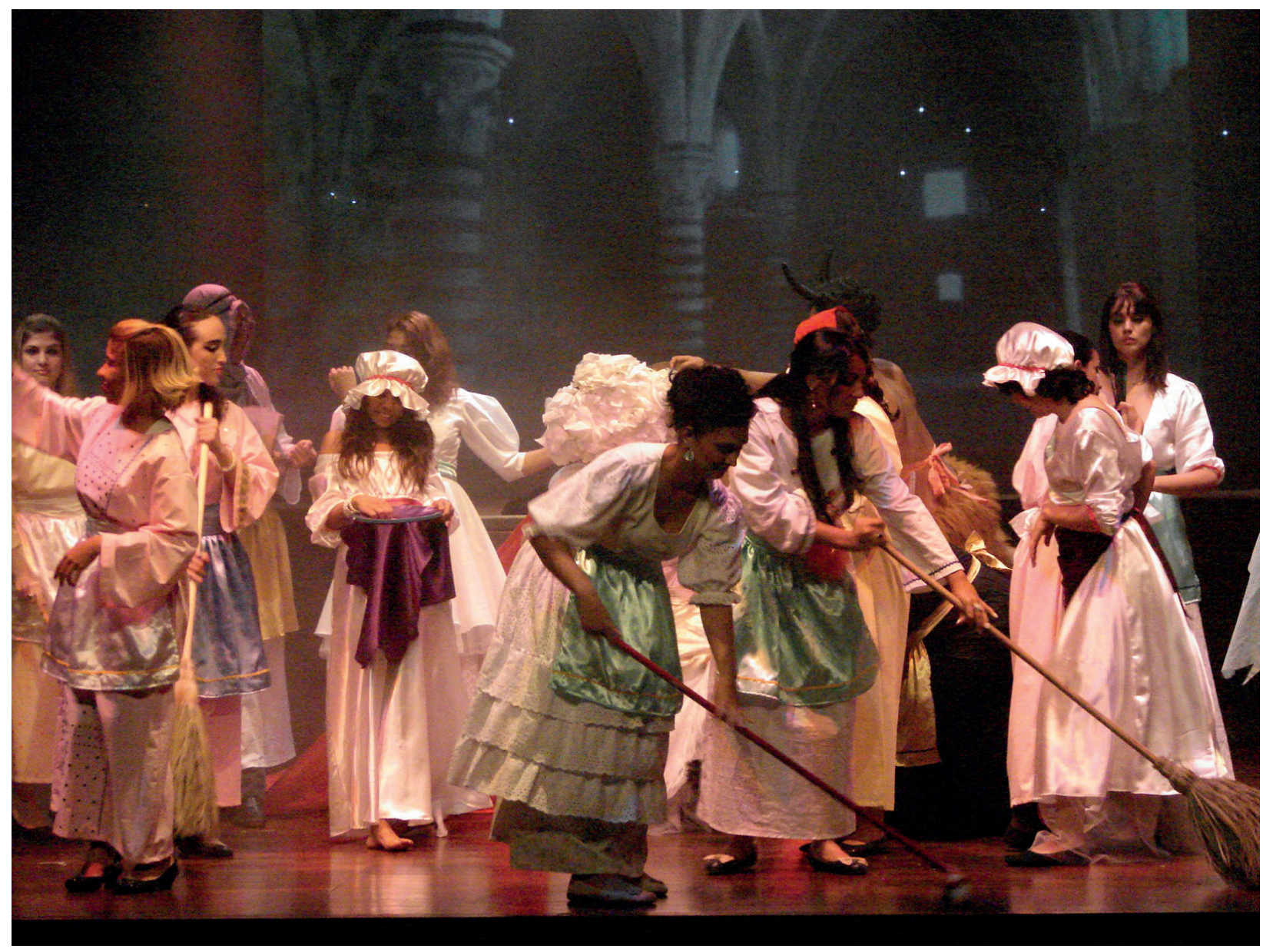

Figura 2 - Alunos do Curso de Teatro da EMAC - EMAC/UFG Cena $O$ reino das virtudes domésticas.

Fonte: Fabrícia Vilarinho.

A comédia mágica "A loteria do diabo" foi a que chegou a nossas mãos com o objetivo de elaboração de uma montagem teatral para a abertura do I Simpósio Nacional de Musicologia promovido pela Escola de Música e Artes Cênicas (EMAC) da Universidade Federal de Goiás (UFG) em parceria com o III Encontro de Musicologia Histórica, promovido pelo Centro de Estudos de Musicologia e Educação Musical da Universidade Federal do Rio de Janeiro (UFRJ).

A obra escolhida é de autoria de Joaquim Augusto d'Oliveira (1827-1904) e de Francisco Palha (18241890), com música de Joaquim Casimiro Júnior (1808-1962). A investigação sobre o gênero surgiu no decorrer das pesquisas da Professora Dra. Vanda Bellard Freire sobre "Ópera Brasileira em Língua Portuguesa" e "Registro Patrimonial de Manuscritos da Biblioteca Alberto Nepomuceno/ UFRJ", a partir de uma partitura em cuja capa figurava o título "Rainha da Noite (mágica)".
Almejando conhecer o motivo por essas peças receberem o nome de mágica, Vanda Freire aprofunda a sua pesquisa e redescobre esse gênero dramático-musical pouco explorado pela literatura musical e teatral. Se deslocando para Portugal a professora ingressa num Pósdoutoramento na Universidade Nova de Lisboa. No bojo de sua pesquisa, sua trajetória a conduz às mágicas em Portugal, conseguindo recolher um vasto e importante material sobre a existência delas nas cidades de Lisboa, Porto e até nos Açores. Nesse estágio da pesquisa Freire localiza a partitura e o libreto da comédia mágica A loteria do diabo. A obra foi encenada em Lisboa em 1858, no Teatro de Variedades, fazendo muito sucesso. ${ }^{12}$

A mesma autora aponta que existem informações de a peça A loteria do diabo foi encenada anos mais tarde, no Rio de Janeiro (Theatro Sant'Anna), com música de Henrique Alves de Mesquita, seguindo a prática usual dos produtores de mágicas, de 


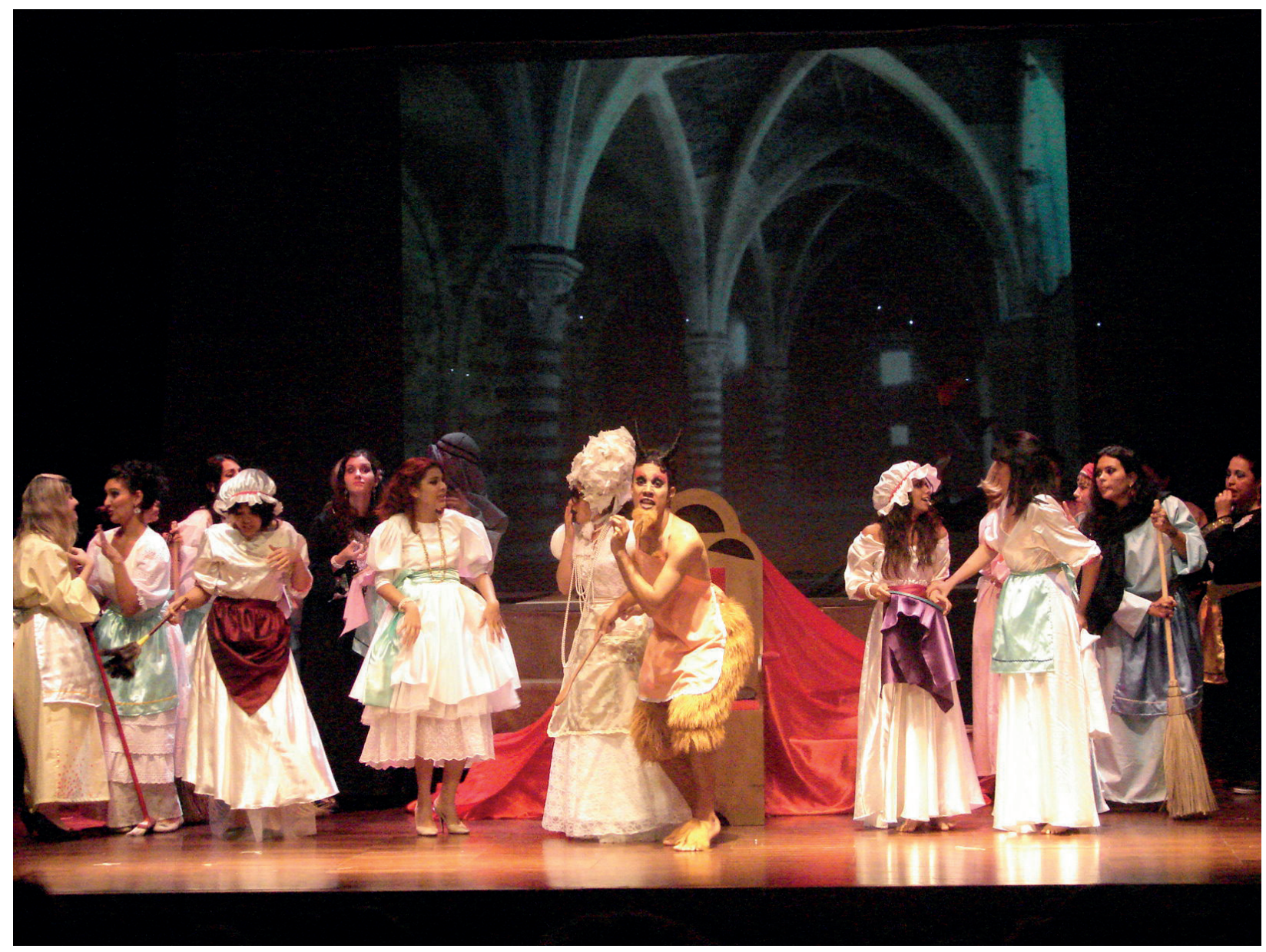

Figura 3 - Alunos do Curso de Teatro da EMAC - EMAC/UFG Cena $O$ reino das virtudes domésticas e Sataniel. Fonte: Fabrícia Vilarinho.

adaptar ou modificar o libreto e a partitura, conforme o local em que eram apresentadas. No Brasil e em Portugal as apresentações de A loteria do diabo foram grande sucesso de bilheteria, como comumente acontecia com esses espetáculos, cujo principal atrativo, para o público, era um ambiente mágico e juntamente com os efeitos cênicos que davam vida ao conteúdo fantástico e a história.

A peça A loteria do diabo apela para muitos recursos especiais em cena, onde vários objetos são transformados em outros. A fantasia e alegorias, que beiram ao absurdo, se misturam como algo natural e tolerável. Há na peça uma ligeira sátira ao universo árabe com gênios e desejos mágicos, a autoridade de homens religiosos e velhacos espertalhões, em uma epopeia que busca o restabelecimento do reino roubado por encantamento de um dos protagonistas, que percorrerá, junto com uma espécie de escudeiro às avessas, mundos inusitados com seus perigos e suas peculiaridades em busca de um amor e de seu reino por meio de um pacto com o diabo, que através de uma loteria mágica sorteia números que representam sortilégios ou mesmo maldições nas perambulações por esses mundos. Em contrapartida, a cada vez que o protagonista retira números da sacola mágica, Ihe é diminuído em semanas de vida o número que aparece.

Os personagens que povoam o universo das comédias mágicas, sempre composta por grande elenco, possuem características específicas representando tipos que se repetem em várias delas:

As mágicas apresentam personagens variados, que compõem um "perfil" básico repetido em diversos espetáculos: nobres (príncipes, princesas, reis, rainhas), entes fantásticos (gênios, fadas, diabos, gnomos, espíritos, diabos), elementos diversos personificados (forças da natureza, moedas, virtudes, pecados), personagens bucólicos 
(camponeses, aldeões) e personagens "populares" (aias, soldados, guardas, escudeiros, mercadores). ${ }^{13}$

Essa grande quantidade de personagens "aparentemente desencontrados tem, no fio condutor flexível, sua coerência, revelando o caráter não linear das mágicas"14. Esse fio condutor, destacado pela autora, é a própria história que gira em torno de temas fantásticos. No caso da A loteria do diabo, o enredo não é linear, possui a temática fantástica e se passa em um ambiente exótico, no caso o Oriente, o que permite efeitos surpreendentes, fantasiosos e até mítico, uma vez que a obra retrata uma realidade não familiar e distante do povo português num período em que as fronteiras eram difíceis de serem quebradas, o que dá margem a imaginação quando a cultura de outros povos. Como seriam estes povos exóticos? Assim foi desenhada uma espécie de cartografia imaginaria elaborada a partir de visualidades e de muitas camadas de subjetividades.

Outro ponto que nos chamou a atenção quanto aos personagens das comédias mágicas é a presença do diabo em todas elas. Nesse texto em especial, não só o diabo é um dos personagens principais, mas o título da obra faz também referência ao mesmo.

A concepção de diabo "popular" fornece base interessante para entender os personagens diabólicos presentes nas mágicas. Periódicos oitocentistas fazem referências diversas ao diabo, permitindo uma aproximação com o universo ideológico da época. ${ }^{15}$

A elaboração do personagem diabo da comédia mágica que estamos abordando, se deu basicamente pela música através de "desenhos rítmicos, silêncios, interrupções expressivas e nuanças harmônicas, que contribuem para caracterizar irreverência, comicidade e ludíbrio. A música participa da elaboração dessas características [...]"16. No trabalho de construção do personagem "Sataniel" (o diabo) utilizou-se a música e seus compassos para construir o corpo e o andar do personagem, de tal modo que sempre que o mesmo estava em cena os músicos tocavam a mesma música de referência, criando um registro com intuito de atravessar o espectador. Esta foi incorporada ao personagem e essa união se tornou indissolúvel ao longo de todo o espetáculo, criando desenhos corporais e sonoros. Também definimos as pesquisas corporais a partir de estudos sobre os faunos, os satíricos, os gênios das florestas, monstros temíveis da mitologia grega. Entre estes meio homens e meio animais, usamos com também como referência imagética os trabalhos de Valslav Nijinski no balé I'aprésmidi dún faune.

Outro personagem que merece destaque nas mágicas é a presença do coro religioso. No caso da comédia mágica "A loteria do diabo" o coro introduz os dervixes ${ }^{17}$.

No libreto, essa passagem da música é descrita como "solene e grave" e tem a seguinte letra:

Respeitava, derviche, tu que abrandas

Do Deus potente e justo as iras cruas

Faz descer dessas mãos tão venerandas

Sobre a nossa cabeça as bençãos tuas!18

A mesma autora ainda sugere que após a saída dos dervixes a música muda de uma melodia solene e grave para um vivíssimo. No caso da nossa montagem, após a saída dos monges, a música que passa a ser executada é a mesma música da primeira cena, a música da feira árabe que abre o espetáculo. Na continuidade da cena, após a saída dos dervixes, a personagem Amina entra em cena procurando Azaim. "Essa pequena descrição de um trecho da primeira cena da mágica A loteria do diabo evidencia o que se vai encontrando ao longo de todas as mágicas: a música construindo - caráter das cenas e dos personagens sem se separar do texto e da encenação". 19

A montagem da comédia mágica A loteria do diabo, na Escola de Música e Artes Cênicas com os alunos do Curso de Teatro e do Curso de Música, ocorreu após a transcrição do texto e a adaptação da obra. $O$ arquivo que nos foi entregue, no primeiro momento, foi um libreto original português e trazia um texto que, se montado na íntegra, renderia três horas de espetáculo, no mínimo. Similar ao conto Ali Babá e os quarenta ladrões ${ }^{20}$.

A comédia mágica A Loteria do Diabo, narra a história do príncipe perdido Azaim que para recuperar seu reino faz um pacto com o diabo recebendo assim, uma sacola de loteria magica, onde cada dado retirado é o número presente e que determina o tempo de existência do nosso personagem. Essa sacola mágica é só um dos recursos para que o protagonista consiga percorrer sete reinos encantados e superar todos os obstáculos. O companheiro de viagem do nosso herói é Abdala, um idoso ambicioso e 


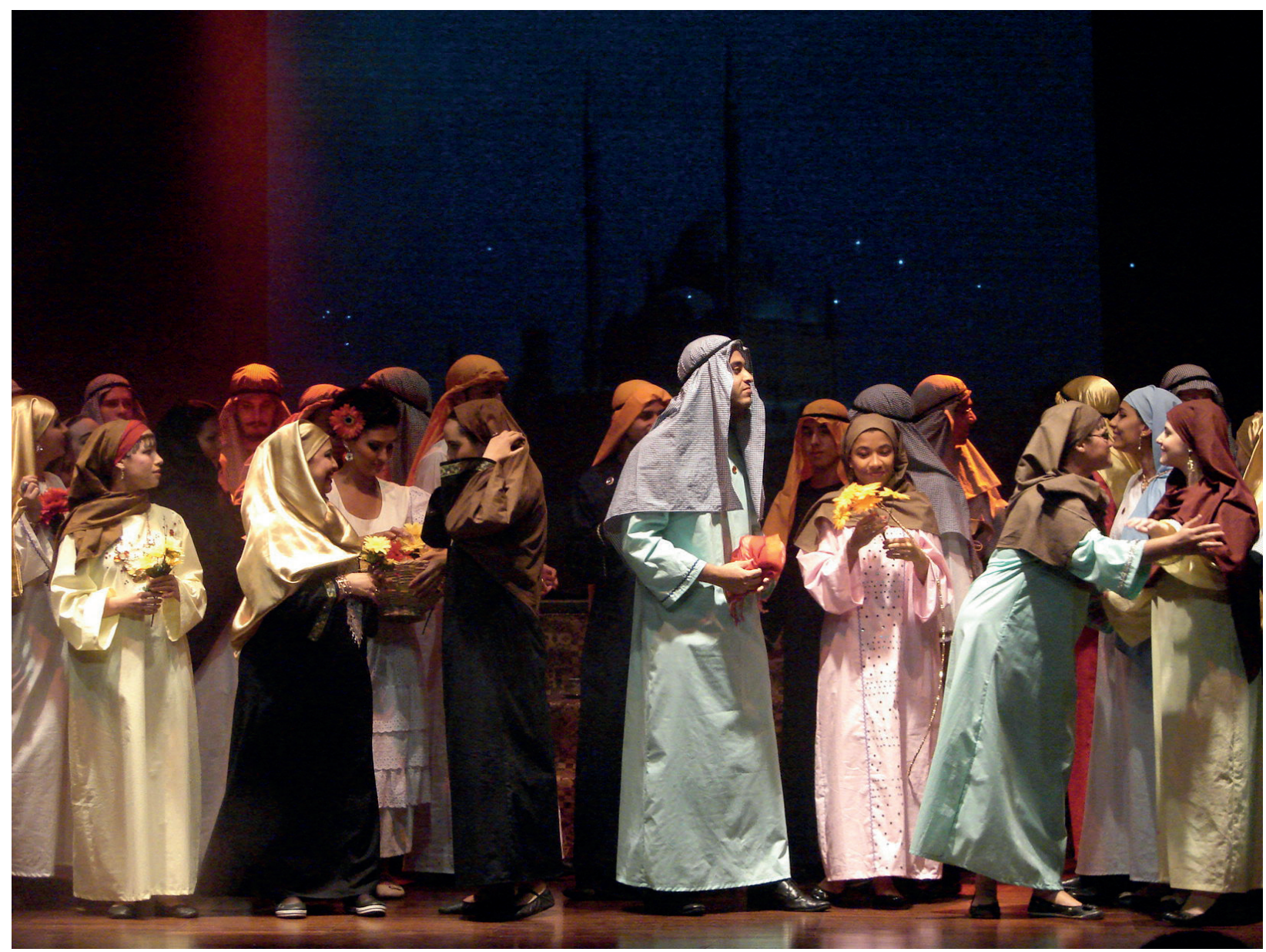

Figura 4 - Alunos do Curso de Teatro da EMAC - EMAC/UFG

Cena das donzelas.

Fonte: Fabrícia Vilarinho.

atrapalhado que confunde ainda mais a viagem de Azaim. O prêmio para a empreitada será além de reaver seu reino e tomar a mão da jovem e linda Amina.

Ressaltamos que para a concretização dessa montagem foi necessário se fazer uma atualização do texto quanto a sua grafia e em seguida uma adaptação da obra para que esta fosse encenada em, no máximo, uma hora e meia de duração. $\mathrm{Na}$ obra original existem 38 personagens fixos e uma infinidade de coadjuvantes entre cavaleiros gregos, árabes, beduínos, judeus, o povo oriental de ambos os sexos, dervixes, diabos, entre outros. Para o nosso trabalho contávamos apenas com 15 alunos/atores do curso de teatro, 39 alunos/coralistas e 40 músicos/alunos do curso de música.

A montagem foi preparada em dois meses e por isso cada professor da equipe do projeto se responsabilizou por sua parte, mas com roteiro delineado coletivamente na perspectiva de conjunto. Nós, trabalhamos o texto, o professor de canto preparou o coral e o professor de regência preparou a orquestra a partir das partituras. Quanto à parte teatral, como já mencionamos, a adaptação foi imprescindível, pois a linguagem precisava ser contemporizada para facilitar o entendimento do texto.

Importante destacar que a investigação sobre o gênero e consequentemente a descoberta dessa comédia mágica, em especial, surgiu durante as pesquisas "Ópera Brasileira em Língua Portuguesa" e "Registro Patrimonial de Manuscritos da Biblioteca Alberto Nepomuceno/ UFRJ". Isso por conta de uma partitura em cuja capa figurava o título "Rainha da Noite (mágica)". A necessidade para entender esse gênero dramático musical conduziu a pesquisadora Wanda Freira a uma pesquisa especifica, culminando na 
redescoberta do referido gênero já esquecido pela literatura sobre música e sobre o teatro no Brasil.

A pesquisadora descobriu na sequência as mágicas em Portugal levantando assim um extenso material sobre a existência delas nas cidades de Lisboa, Porto e até nos Açores. Nessa empreitada a partitura e o libreto da mágica A Loteria do Diabo foram encontrados em arquivos portugueses. A obra foi encenada em Lisboa em 1858, no Teatro de Variedades, fazendo muito sucesso. A música dessa versão foi do compositor português Casimiro Júnior, e o libreto de Joaquim Augusto de Oliveira e de Francisco Palha, autores teatrais. Sabe-se também que essa obra foi encenada mais tarde no Rio de Janeiro (Theatro Sant'Anna), com música de Henrique Alves de Mesquita, seguindo a prática usual dos produtores de mágicas, de adaptar ou modificar o libreto e a partitura, conforme o local em que eram apresentadas. No Brasil e em Portugal as apresentações de A Loteria do Diabo tiveram grande repercussão e agradaram o público da época. $\mathrm{Na}$ verdade esse tipo de espetáculo fazia muito sucesso pelo caráter mágico cujos efeitos cênicos configuravam um enredo absolutamente fantástico.

A nossa montagem da Loteria do Diabo foi apoiada pelo Projeto de Pesquisa "Teatro Musical - Rio de Janeiro e Lisboa" (UFRJ) e do Projeto de Extensão "Teatro Musical em Cena" (UFRJ) sob a coordenação da Prof.( Dra. Lima Bellard Freire. A Editoração da partitura da mágica, a partir do original localizado pela pesquisadora foi de Flávio de Carvalho.

Sobre a adaptação o autor Helio Maia ${ }^{21}$ nos relata que a peça original foi escrita em um português arcaico e rico de expressões não usuais em nossos dias. Para adaptá-la foi necessário a reescrita no português atual e um estudo das expressões usadas para se fazer uma atualização das mesmas. Aquelas expressões que eram facilmente entendidas por serem claras e dizerem exatamente o que significavam, permaneceram inalteradas.

Dada à extensão da peça original, foi necessário suprimir alguns atos sem prejuízo à ideia geral e outros muito longos, que não podiam ser suprimidos sem prejuízo da ideia central, foram transformados em narrativas. Para isso, um dos personagens, o "escudeiro" do protagonista foi transformado em uma espécie de narrador e o mesmo, em muitas partes da peça que era para ser encenada, apenas narrava o ocorrido, abreviando o texto e the conferindo maior fluidez. Para transformação do texto original nessas narrativas mencionadas, usou-se um estilo trovadorístico o que conferiu a essa parte narrada uma suave cadência que facilitou a memorização das longas narrações desse personagem se adequando ao lirismo proposto na parte musical da peça. Como um dos elementos mais marcantes da peça eram as inserções musicais, evitou-se suprimir da narrativa, as partes onde havia música e canto.

No geral, mesmo havendo uma redução substancial do texto original na adaptação, ainda assim a peça continuou extensa, porém, uma redução mais drástica, poderia afetar sobremaneira a ideia original e até mesmo desvirtuá-la.

Já trabalho com as partituras, segundo o Professor Flávio Carvalho 22 , foi pautado por seguir na íntegra o que o compositor escreveu, baseados no original autógrafo. As adaptações não se deram na escrita musical, mas no uso das ferramentas (softweres) que dispomos para a edição das partituras, que nem sempre preveem formas mais antigas de formato de escritura musical. Na atualização das partituras ocorreu também a modernização do português do texto escrito, pensando em facilitar a fluência de leitura dos cantores.

Esta experiência nos proporcionou viver uma relação sofisticada e múltipla, polissêmica, onde muitas vozes ecoaram. É delicada a relação de juntar fragmentos de tempos não mais atuais, sem destituir as complexidades da obra, pensando no presente, e na sua relação de pertencimento, e trazê-lo de volta sem comprometer sua alma e seus sentidos.

Destarte, o tempo incide na memória e essas vozes trazem um passado esquecido, mas nem por isso menos importante. A pesquisa sobre uma obra escrita e encenada em outro século nos remete a tentativa de recuperação, de ressignificação de um tempo perdido. Tanto para o teatro, como para a música e para a dança foi necessário se revisitar cada área em um passado esquecido e tentar trazer para a contemporaneidade as peculiares de cada expressão artística. Esse foi o maior desafio, acomodar harmoniosamente cada linguagem e criar uma única expressão artística integrada, sem sobreposição de nenhuma. Assim foi com a comédia mágica a Loteria do diabo. 
No atual momento histórico percebemos claramente uma tendência individualista e fragmentada da modernidade impondo-se, como desafio frente às tradições quase esquecidas, ou recuperadas por estudiosos, sendo estas um pedaço de nossa história que é particular. Acreditamos, no entanto que através da arte as tradições podem ser revistas, uma vez que a arte se expressa via corpo, voz, falas, gestos e as marcas da memória. Nas artes integradas convivemos com um fazer constituído de paixão e de integridade. Neste lugar o saber e o fazer artístico coexistem.

Pensamos numa arte, onde o teatro, a música e a dança, se encontram, constituída no sujeito, um fazer humano, de "gente em cena" que traduz e transgride a própria vida. Um tear artesanal e misturado a fios e a cores, mas que remete às memórias vividas. As memórias dos outros que passaram a ser também nossas. Uma colcha de vidas que foi misturada aos poucos, de forma singular, somando as experiências marcadas no corpo:

[...] experiência, ao mesmo tempo, possibilitadora da inscrição no corpo de emoções e paixões, de construções de sentidos muitas vezes intransmissíveis, mas singulares - diga-se passíveis de serem ressignificados pela sensibilidade $e$ racionalidade não instrumental, de poetasalegoristas, que ousam afirmar-se como pessoas, perante as incertezas do avanço da modernidade capitalista na contemporaneidade. ${ }^{23}$

Nosso contato com os atores, cantores e músicos, foi marcado pelo contexto, pela interação, pela experiência vivida, pela maturidade do encontro. Enraizamos nossas práticas em uma metodologia qualitativa e empírica, que não nos imobilizasse, mas principalmente que fosse plural, dialógica, com dissonâncias e ressonâncias no nosso processo de criação.

Neste contexto, as imagens, os textos, as falas, as músicas, o diálogo, as histórias do passado e do presente se amalgamaram e tudo serviu de contextualização, de matéria viva para o processo criativo. Nesta complexa, difícil e rica teia, estruturamos o conhecimento, a partir das possibilidades dadas pela ciência e pela arte.

No decorrer da pesquisa, fomos interceptadas pelos diversos aprendizados e trocas. Algo de não dito presentes nos processos cênicos nos interessam, como o silêncio que fala no gesto e os textos que estão no corpo. Então, memória é algo que está ligada às situações de nossas vidas e resignificamos dores, alegrias e frustrações. Propusemos um processo em movimento, no qual deste retroceder buscamos os fatos, os afetos e esquecemos outros. Tratamos das memórias dos outros.

Quando se fala de memória diz-se de coisas esquecidas, coisas de um passado distante, uma perspectiva estreita de memória, para muitos, apenas um resgate do passado, apenas uma leitura romântica e nostálgica para a história da vida ou da sociedade.

Portanto, faz-se necessário colocá-la em outra composição, em outra noção de memória. Uma memória afetiva e corporal, compartilhada e individual ao mesmo tempo. Constatamos assim que somos instrumentos nos processos de reconstrução da memória de pequenos grupos ou de indivíduos, pois trazemos a possibilidade do registro dos fenômenos sociais e culturais.

Imbuídos do esforço de se passar às novas gerações um cabedal de conhecimentos acumulados, transformados e recriados, e a "contrapelo", ${ }^{24}$ como se buscamos, sobretudo, uma arte que não liquidifica as experiências, pois acreditamos que são nestas resistências em que o sujeito se fortalece e o coletivo se constitui, amparando-se na própria noção de história. Os vários fragmentos trazem um passado a ser compreendido no presente. Esta reconstrução é possível quando o grupo é capaz de compartilhar a memória e "ser" atuante e agente de sua própria memória.

Em todo o percurso, grande e instigante, o impacto foi realmente sobre as visões de mundo que se confrontaram. Também apareceram os preconceitos e os estranhamentos, mas superouse entre empatias, afetos e "co-aprendizados". Foi fundamental estar atentas ao que se poderia oferecer a equipe e ao mesmo tempo, ao que se deveria aprender com eles, uma vez que envolvia muitas áreas do conhecimento. Pesquisadores querem reconstruir o passado e os narradores querem projetar a sua imagem nos relatos onde o passado se torna relevante no presente. Esta é uma ação dialética, portanto, é fundamental para uma construção de conhecimento. No palco surge algo de novo, ancorado aos rastros da história, mas contemporanizado em uma experiência mágica e única. 
As histórias se alteram, os contos de fadas se transformam, os mitos morrem. Também as versões do próprio passado mudam, pois as histórias são abertas, provisórias e parciais. Cada história é única e as demandas dos indivíduos podem trazer conformidades ou mudanças, por isso as questões teóricas, artísticas e metodológicas são de extrema importância. Então entre a ficção e a realidade existem diálogos e concepções que fazem cruzar tempos, discursos e práticas.

Os antigos gregos já conheciam Poesia, filha de Mnemosine, a deusa da memória, "o poeta, o mais criativo de todos os entes, é apenas um ser possuído pela memória." ${ }^{25}$. Mais importante foi pensar que a arte não é algo que tenha fim em si mesmo, como um produto acabado, mas a possibilidade de se recuperar principalmente a capacidade nossa de deixar rastros e principalmente de se encontrar nas suas e nas memórias dos outros. Memória e imaginação não se opõem como quer nosso senso comum.

Certamente não queremos respostas prontas e a arte que tratamos é povoada de poesia, de memória e de narrativas que se constituem no tempo, no espaço, na tensão e no conflito. É a tentativa de olhar para o passado pensando no presente e na possibilidade de melhor entender as tensões da modernidade e da cultura. $O$ teatro, a música e a dança como artes da memória, ao invés de acenar apenas para um passado remoto, apontam para novas produções de sentidos, de conhecimentos e potencializam o sujeito, pois a experiência é coletiva se ancora e se reinventa a partir do outro.

\section{NOTAS}

01. Este estudo se constitui de uma parceria realizada pela EMAC - Escola de Música e Artes Cênicas da UFG com o grupo de pesquisa Centro de Estudos de Musicologia e Educação Musical da Professora Dra. Vanda Freire da UFRJ.

02. Transdiciplinaridade no sentido apresentado por Lima de Freitas, Edgar Morin e Basarab Nicolescu na Carta da Transdiciplinaridade elaborada e discutida no Primeiro Congresso Mundial da Transdisciplinaridade, Convento de Arrábida, Portugal, 2-6 novembro 1994. "A transdisciplinaridade é complementar à abordagem disciplinar; ela faz emergir novos dados a partir da confrontação das disciplinas que os articulam entre si; oferece-nos uma nova visão da natureza da realidade. $\mathrm{A}$ transdisciplinaridade não procura a mestria de várias disciplinas, mas a abertura de todas as disciplinas ao que as une e as ultrapassa". (Carta da Transdisciplinaridade, art. $3^{\circ}$ ).

03. FREIRE, Vanda Bellard. Óperas e mágicas em salões em teatros do Rio de Janeiro: final do século $X I X$ e início do século XX. Latim American Music Review, vol.25, n. 1, Texas, 2004. Grifos da autora

04. FREIRE, Vanda Bellard. O mundo maravilhoso das mágicas. Rio de Janeiro: Contra Capa/ PAPERJ, 2011.

05. BERTHOLD, Margot. História mundial do teatro. São Paulo: Perspectiva, 2000. p. 330.

06. FREIRE, Vanda Bellard. O mundo maravilhoso das mágicas. Rio de Janeiro: Contra Capa/ PAPERJ, 2011. p.15.

07. FREIRE, Vanda Bellard. Óperas e mágicas em salões em teatros do Rio de Janeiro: final do século XIX e início do século XX. Latim American Music Review, vol.25, n. 1, Texas, 2004. P.

08. A Lanterna mágica é o antecessor dos aparelhos de projeção moderno. Consiste num instrumento que projeta imagens registadas em suporte transparente. Estas imagens são estáticas, sendo a sua deslocação no interior do projetor o único artifício de movimento projetado numa tela. Esse instrumento surgiu no século XVII.

09. Gênero de entretenimento e de variedades predominante nos Estados Unidos e Canadá do início dos anos 1880 ao início dos anos 1930. Era apresentado em salas de concerto e consistia em apresentações de cantores populares e de literatura burlesca.

10. FREIRE, Vanda Bellard. O mundo maravilhoso das mágicas. Rio de Janeiro: Contra Capa/ PAPERJ, 2011.

11. FREIRE, Vanda Bellard. O mundo maravilhoso das mágicas. Rio de Janeiro: Contra Capa/ PAPERJ, 2011.

12. FREIRE, Vanda Bellard. O mundo maravilhoso das mágicas. Rio de Janeiro: Contra Capa/ PAPERJ, 2011. 
13. FREIRE, Vanda Bellard. O mundo maravilhoso das mágicas. Rio de Janeiro: Contra Capa/ PAPERJ, 2011. p. 49. (parênteses da autora).

14. FREIRE, Vanda Bellard. O mundo maravilhoso das mágicas. Rio de Janeiro: Contra Capa/ PAPERJ, 2011. p.51.

15. FREIRE, Vanda Bellard. O mundo maravilhoso das mágicas. Rio de Janeiro: Contra Capa/ PAPERJ, 2011. p.52.

16. FREIRE, Vanda Bellard. O mundo maravilhoso das mágicas. Rio de Janeiro: Contra Capa/ PAPERJ, 2011.

17. Monges muçulmanos; dervis; daroês. A maioria dos dervixes leva uma vida nômade de abnegação, vivendo as esmolas. A palavra dervixe vem do persa e significa mendigo, ou mendigo religioso.

18. FREIRE, Vanda Bellard. O mundo maravilhoso das mágicas. Rio de Janeiro: Contra Capa/ PAPERJ, 2011. p.58.

19. FREIRE, Vanda Bellard. O mundo maravilhoso das mágicas. Rio de Janeiro: Contra Capa/ PAPERJ, 2011. p. 58.

20. O conto original é baseado na Arábia préislâmica. Neste conto está descrito nas aventuras de Ali Babá e os quarenta ladrões que faz parte do clássico livro das "mil e uma noites ou Noites na Arábia". O personagem título é um famoso ladrão que conta com a ajuda de seus 40 homens para livrá-lo de várias armadilhas e acompanhá-lo em suas inúmeras peripécias.

21. Professor Mestre pela UNB, formador do Curso de Licenciatura em Arte Cênicas EAD/PARFOR/ UAB Universidade Federal de Goiás.

22. Professor Adjunto IV de Canto da Universidade Federal de Uberlândia. Como participante do Grupo de pesquisa de musicologia, foi o responsável pela transcrição das partituras da peça "A Loteria do Diabo".

23. GALZERANI, Maria Carolina Bovério. Percepções Culturais do Mundo da Escola: em Busca da Rememoração. Campinas, Anais do III encontro nacional de pesquisadores do ensino de história. P. 98-109. 2004. p. 288.
24. BENJAMIN, Walter. Magia, Técnica, Arte e Política: Ensaios sobre Literatura e História da Cultura. SP: Brasiliense, 1994.

25. AMADO, Janaína. O grande mentiroso: tradição, veracidade e imaginação em história oral. História, SP: v. 14, p. 125-136, 1995. p.127.

\section{REFERÊNCIAS}

AMADO, Janaína. 0 grande mentiroso: tradição, veracidade e imaginação em história oral. História, SP: v. 14, p. 125-136, 1995.

BENJAMIN, Walter. Magia, Técnica, Arte e Política: Ensaios sobre Literatura e História da Cultura. SP: Brasiliense, 1994.

BERTHOLD, Margot. História mundial do teatro. São Paulo: Perspectiva, 2000.

FREIRE, Vanda Bellard. 0 mundo maravilhoso das mágicas. Rio de Janeiro: Contra Capa/PAPERJ, 2011.

FREIRE, Vanda Bellard. Óperas e mágicas em salões em teatros do Rio de Janeiro: final do século XIX e início do século XX. Latim American Music Review, vol.25, n. 1, Texas, 2004.

FREIRE, Vanda Bellard. Óperas e mágicas em salões em teatros do Rio de Janeiro: final do século XIX e início do século XX. Latim American Music Review, vol.25, n. 1, Texas, 2004.

GALZERANI, Maria Carolina Bovério. Percepções Culturais do Mundo da Escola: em Busca da Rememoração. Campinas, Anais do III encontro nacional de pesquisadores do ensino de história. P. 98-109. 2004. 


\section{SOBRE AS AUTORAS}

Valéria Maria Chaves de Figueiredo é doutora em Educação pela Faculdade de Educação da Unicamp (2007). Mestre em Artes pelo Instituto de Artes da Unicamp (1997). Licenciada em Educação Física pela Universidade Gama Filho (1988), formação em dança contemporânea e educação somática pela atual Faculdade Angel Vianna (1990). Professora Associada da Universidade Federal de Goiás atua nos cursos de Dança e Teatro. Líder do laboratório de pesquisa interdisciplinar em Arte da Cena - LAPIAC/FEFD/UFG, editora setorial da revista "Pensar a Prática" da FEFD/UFG e atual coordenadora de estágio e do Pibid/Dança.

Urânia Auxiliadora Santos Maia de Oliveira é doutora em Educação pela Universidade Federal da Bahia na área de Teatro-Educação (2007), Mestre em Artes Cênicas pela Universidade Federal da Bahia (2002). Graduada em Licenciatura em Teatro pela Universidade Federal da Bahia (1998). Atualmente é Professora Adjunta IV da Universidade Federal da Bahia. Foi Professora Adjunta II da Universidade Federal de Goiás da EMAC - Escola de Música e Artes Cênicas, Coordenadora do Curso Licenciatura em Artes Cênicas EAD/PARFOR/UAB e Coordenadora do subprojeto Artes Cênicas - PIBID. 